\title{
EDITORIAL
}

\section{Antipathy against SDD is justified: Yes}

\author{
Jean-François Timsit ${ }^{1,2^{*}}$ and Matteo Bassetti ${ }^{3,4}$
}

๑ 2018 Springer-Verlag GmbH Germany, part of Springer Nature and ESICM

\section{Introduction}

In his Nobel Prize lecture in 1945, Fleming pointed out the easiness of making microbes resistant to penicillin "by exposing them to concentrations not sufficient to kill them". In a famous lecture [1], Rice generalized this finding and concluded that the most reasonable strategy to minimize resistance is to "stop irritating the bacteria: (1) before therapy begins by treating only patients who are truly infected; (2) during therapy, avoiding the use of combination therapy when a single agent will suffice; (3) at the tail end of therapy, by treating only for as long as is required to cure the infection."

These voices of reason were clearly comforted by numerous studies demonstrating that an increase in the use of one particular antimicrobial is always associated with the emergence of strains or species that are resistant to that antimicrobial [2]. Many studies demonstrated the link between antibiotic use and antibiotic resistance, both at a unit and individual level, and on the infecting flora as on the gut microbiota.

\section{Emergence of resistant bacteria worldwide: a need for antibiotic stewardship programs}

This voice is particularly critical since the epidemiological situation of resistance is catastrophic. The conjunction of uncontrolled use of antimicrobials and the diffusion in the community of multidrug-resistant organisms (MDRO) and now extensively drug-resistant bacteria is tricky. Furthermore, the worldwide diffusion of these extensively resistant bacteria is fostered by an increasing access to travel and migration.

\footnotetext{
*Correspondence: jean-francois.timsit@bch.aphp.fr

1 UMR 1137, IAME Team 5, DeSCID: Decision Sciences in Infectious Diseases, Control and Care INSERM, Université Paris Diderot, Sorbonne Paris Cité, Paris, France

Full author information is available at the end of the article
}

For contrasting viewpoints, please go to https://doi.org/10.1007/s00134018-5144-6 and https://doi.org/10.1007/s00134-018-5198-5.
Nowadays, transmission of MDRO occurs not only in hospitalized patients but also in healthy subjects. In the community, extended-spectrum beta-lactamase-producing enterobacteria (ESBL-PE) carriage rates reach 6-10\% in Europe, $10-12 \%$ in the USA, $40-50 \%$ in eastern Mediterranean countries, and above $70 \%$ in Southeast Asia [3]. Acquisition rates of ESBL-PE by European travelers are about $30 \%$ in America, $40 \%$ in Africa, and $70 \%$ in Asia [4]. ESBL-PE acquisition after travel is able to diffuse to other family members in $12 \%$ of the cases [5]. ESBL-PE carriage in healthy people is $14 \%$ worldwide on average and increases by more than $5 \%$ per year [6]. Even in the Netherlands ESBL-PE carriage is $8.6 \%$ in healthy people, favored by recent antimicrobial use [7].

The spread of carbapenemase-producing gram-negative bacteria (GNB) in the community mimics the ESBLPE pandemic [8]. A systematic review showed a rate of $5-10 \%$ in the USA, and up to $29.5 \%$ in one study from Taiwan. The diffusion of carbapenemases in hospital plays also an important role in amplifying the spread of resistance. In both community and hospital settings, antibiotic therapy favored resistance maintenance in the microbiota and resistance diffusion. Colistin remains one of the major last-resort therapies to treat infections with carbapenemase-producing GNB.

The key domains of antibiotic stewardship programs have been discussed in a recent international expert panel [9]. Efforts should be focused on an appropriate and early adequate therapy of infection limiting the antibiotic colonization pressure. The key messages of this task force are use better risk stratification, early diagnosis of infection processes, optimization of targeted therapy, and prevention of nosocomial infection and cross-transmission.

\section{Selective digestive decontamination with antimicrobials: more risks and threats than individual benefits (Table 1)}

Among available prevention strategies, decontamination therapy remains clearly controversial. Indeed,

\section{Springer}


Table 1 Potential advantages and disadvantages of SDD/SOD with a short course of IV antimicrobial

\begin{tabular}{|c|c|}
\hline Advantages & Disadvantages \\
\hline $\begin{array}{l}\text { Overall reduction of infections in ICUs with low levels of antibiotic resist- } \\
\text { ance }\end{array}$ & Temporal increase in resistant bacteria in recipients of SDD \\
\hline Better ICU survival (demonstrated in meta-analyses only) & $\begin{array}{l}\text { Topical use of antibiotics (against the modern concept of antimicrobial } \\
\text { stewardship) }\end{array}$ \\
\hline $\begin{array}{l}\text { Lower incidence of carriage and infections with antibiotic-resistant } \\
\text { bacteria }\end{array}$ & Benefit demonstrated only in centers with low level of antibiotic resistance \\
\hline $\begin{array}{l}\text { Lower use of systemic antibiotics in centers where SDD/SOD has been } \\
\text { used }\end{array}$ & No impact on mortality \\
\hline \multirow{7}{*}{$\begin{array}{l}\text { Eradication of cephalosporin-resistant Enterobacteriaceae from the intesti- } \\
\text { nal tract }\end{array}$} & Increased use of cephalosporin \\
\hline & Increased use of colistin \\
\hline & $\begin{array}{l}\text { Emergence of colistin-resistant strains during persistent gram-negative } \\
\text { bacteria colonization over the study period }\end{array}$ \\
\hline & Long-term alteration of the microbiota \\
\hline & Occurrence of a rebound effect after the discontinuation of SDD/SOD \\
\hline & $\begin{array}{l}\text { Where colistin has been used, significant increase in the colistin MIC and } \\
\text { increase of bloodstream infections causes by pathogens intrinsically } \\
\text { resistant to colistin }\end{array}$ \\
\hline & $\begin{array}{l}\text { Where gentamicin has been used for targeted SDD, occurrence of } \\
\text { gentamicin-resistant Enterobacteriaceae }\end{array}$ \\
\hline
\end{tabular}

meta-analyses based on recent studies performed in the Netherlands are in favor of the use of selective oral decontamination (SOD) or selective digestive decontamination (SDD) with a few days of intravenous (IV) antibiotic therapy to decrease nosocomial pneumonia. SDD combining colistin, tobramycin, and amphotericin B with or without vancomycin was associated with a decrease in the rate of ICU deaths when associated with IV antimicrobials (mostly third-generation cephalosporins or fluoroquinolones).

Authors from the Netherlands concluded that only in ICUs with low levels of antibiotic resistance, SDD and SOD improved patient outcome and reduced infections and carriage with antibiotic-resistant pathogens.

Unfortunately, the impact of SOD and SDD without IV antimicrobials did not affect mortality. The very recent cluster cross-over randomized trial RGNOSIS study (ClinicalTrials.gov NCT02208154) comparing the impact of oral care with chlorhexidine, SOD, and SDD without IV antibiotic to a control group in 13 European ICUs and 8665 patients outside the Netherlands was totally negative in terms of rate of bloodstream infections due to MDRO (primary endpoint) (adjusted odds ratios (95\% confidence interval) for day 28 mortality were 1.07 (0.86-1.32), 1.05 (0.85-1.29), and $1.03(0.80-1.32)$ for chlorhexidine mouthwash, SOD, and SDD versus baseline, respectively), of mortality, and of acquisition of MDRO as was the unit-wide use of systemic antibiotics. Considering the preliminary results of this study, antimicrobial administration by intravenous route is the only component of the SDD regimen that is really protective. The effect of SOD/SDD associated with IV antimicrobials in settings with higher levels of antibiotic resistance remains to be evaluated, as does the efficacy of SDD and SOD in specific patients groups [10].

Knowing that resistance is spreading rapidly, that antibiotics may favor this spread, and that oral and digestive antibiotics contain colistin, the antipathy that we should have against SDD is obvious.

First, the largest study in the analysis shows a reduction in third-generation cephalosporin-resistant GNB after SDD. However, an ecological analysis of this same study shows a temporal increase in resistant bacteria in recipients of SDD and a rebound after discontinuation [11].

Second, short- and long-term data on the impact of SDD on the gut microbiota and emergence of resistance are worrisome. In a single-patient longitudinal study performed by the Utrecht team, Buelow et al. found a 6- to 7 -fold increase in the aminoglycoside resistance genes carried by anaerobic commensals, a resistance easily transferable [12]. In another study, the same group found that four resistance genes providing resistance to aminoglycosides, macrolides, disinfectants, and tetracyclines were significantly more abundant among ICU patients than in healthy subjects [13].

Third, SDD given to patients colonized with ESBL-PE or carbapenemase-resistant enterobacteria carriers was not successful, and even deleterious, especially for the use of colistin that can select non-susceptible organisms. The use of SDD for 5 years during an ESBL-PE outbreak in 
an ICU was associated with a significant increase in the colistin MIC and an increase of bloodstream infections caused by pathogens intrinsically resistant to colistin [14]. In a 2-year Klebsiella pneumoniae carbapenemase (KPC)-producing Klebsiella spp. outbreak involving 90 patients, 14 of them received a 7-day SDD course with colistin-gentamicin, which was not effective to decolonize KPC carriers, but resulted in a $19 \%$ and $45 \%$ increase in the resistance to colistin and gentamicin, respectively, compared to absence of resistance in the control group [15]. Tascini et al. [16] tested the impact of oral decontamination with gentamicin of $50 \mathrm{KPC}$ carriers. Decolonization occurred in 34 cases but gentamicin-resistant KPC appeared in 4/16 persistent carriers.

\section{Conclusion}

We concluded (1) that the benefit of SOD or SDD without IV antimicrobials is largely debatable and terribly hazardous given the spread of carbapenemase-producing GNB in the community; (2) that the use of SOD or SDD regimen with IV antimicrobial is effective in the Netherlands for improving outcome of ICU patients, but this has not been demonstrated outside the Netherlands.

Prevention of cross-transmission and nosocomial infections with an improvement of hand hygiene and continuous quality improvement program integrating a selected bundle of care is the most important strategy to control nosocomial infections and hospital spread of extensively drug-resistant bacteria.

Evidence from the literature shows that, although SOD/SDD provides a short-term benefit, neither a longterm impact nor a control of emerging resistance, especially during outbreaks or in settings with high resistance rates, can be maintained. Nowadays, rates of GNB resistance exceeding $30-35 \%$ in ICUs represent the rule rather than the exception, and carbapenemases are reported worldwide. In the era of carbapenem resistance, antimicrobials such as colistin and aminoglycosides often represent the last option in treating multidrug-resistant GNB. In this setting, the use of "last-resort" antibiotics should be possibly avoided. Given the worldwide dramatic risk of spread of extensively drug-resistant GNB, we consider that an extensive use of SOD/SDD antimicrobial associated with IV antimicrobial as prophylaxis should not be used.

\footnotetext{
Author details

1 UMR 1137, IAME Team 5, DeSCID: Decision Sciences in Infectious Diseases, Control and Care INSERM, Université Paris Diderot, Sorbonne Paris Cité, Paris, France. ${ }^{2}$ APHP Medical and Infectious Diseases ICU, Bichat-Claude Bernard Hospital, Paris, France. ${ }^{3}$ Clinica Malattie Infettive, Azienda Ospedaliera Universitaria Santa Maria della Misericorida, Udine, Italy. ${ }^{4}$ University of Udine School of Medicine, Udine, Italy.
}

Received: 7 March 2018 Accepted: 12 April 2018

Published online: 7 June 2018

\section{References}

1. Rice LB (2008) The Maxwell Finland Lecture: for the duration-rational antibiotic administration in an era of antimicrobial resistance and Clostridium difficile. Clin Infect Dis 46:491-496

2. Timsit JF, Harbarth S, Carlet J (2014) De-escalation as a potential way of reducing antibiotic use and antimicrobial resistance in ICU. Intensive Care Med 40:1580-1582

3. Woerther PL, Burdet C, Chachaty E, Andremont A (2013) Trends in human fecal carriage of extended-spectrum beta-lactamases in the community: toward the globalization of CTX-M. Clin Microbiol Rev 26:744-758

4. Ruppe E, Armand-Lefevre L, Estellat C, Consigny PH, El Mniai A, Boussadia Y, Goujon C, Ralaimazava P, Campa P, Girard PM, Wyplosz B, Vittecoq D, Bouchaud O, Le Loup G, Pialoux G, Perrier M, Wieder I, Moussa N, Esposito-Farese M, Hoffmann I, Coignard B, Lucet JC, Andremont A, Matheron S (2015) High rate of acquisition but short duration of carriage of multidrug-resistant Enterobacteriaceae after travel to the tropics. Clin Infect Dis 61:593-600

5. Arcilla MS, van Hattem JM, Haverkate MR, Bootsma MCJ, van Genderen PJJ, Goorhuis A, Grobusch MP, Lashof AMO, Molhoek N, Schultsz C, Stobberingh EE, Verbrugh HA, de Jong MD, Melles DC, Penders J (2017) Import and spread of extended-spectrum beta-lactamase-producing Enterobacteriaceae by international travellers (COMBAT study): a prospective, multicentre cohort study. Lancet Infect Dis 17:78-85

6. Karanika S, Karantanos T, Arvanitis M, Grigoras C, Mylonakis E (2016) Fecal colonization with extended-spectrum beta-lactamase-producing Enterobacteriaceae and risk factors among healthy individuals: a systematic review and metaanalysis. Clin Infect Dis 63:310-318

7. Reuland EA, Al Naiemi N, Kaiser AM, Heck M, Kluytmans JA, Savelkoul PH, Elders PJ, Vandenbroucke-Grauls CM (2016) Prevalence and risk factors for carriage of ESBL-producing Enterobacteriaceae in Amsterdam. J Antimicrob Chemother 71:1076-1082

8. Kelly AM, Mathema B, Larson EL (2017) Carbapenem-resistant Enterobacteriaceae in the community: a scoping review. Int J Antimicrob Agents 50:127-134

9. De Waele JJ, Akova M, Antonelli M, Canton R, Carlet J, De Backer D, Dimopoulos G, Garnacho-Montero J, Kesecioglu J, Lipman J, Mer M, Paiva JA, Poljak M, Roberts JA, Rodriguez Bano J, Timsit JF, Zahar JR, Bassetti M (2018) Antimicrobial resistance and antibiotic stewardship programs in the ICU: insistence and persistence in the fight against resistance. A position statement from ESICM/ESCMID/WAAAR round table on multi-drug resistance. Intensive Care Med 44:189-196

10. Plantinga NL, Wittekamp B, Cooper B, Brun-Buisson C, Bonten MJ (2018) Decontamination strategies in intensive care units; a cluster-randomized cross-over study. In: 28th European congress of clinical microbiology and infectious diseases; Madrid, Spain; April 21st-24th. Abstract 01131

11. Oostdijk EA, de Smet AM, Blok HE, Thieme Groen ES, van Asselt GJ, Benus RF, Bernards SA, Frenay $I H$, Jansz AR, de Jongh BM, Kaan JA, Leversteinvan Hall MA, Mascini EM, Pauw W, Sturm PD, Thijsen SF, Kluytmans JA, Bonten MJ (2010) Ecological effects of selective decontamination on resistant gram-negative bacterial colonization. Am J Respir Crit Care Med 181:452-457

12. Buelow E, Gonzalez TB, Versluis D, Oostdijk EA, Ogilvie LA, van Mourik MS, Oosterink E, van Passel MW, Smidt H, D'Andrea MM, de Been M, Jones BV, Willems RJ, Bonten MJ, van Schaik W (2014) Effects of selective digestive decontamination (SDD) on the gut resistome. J Antimicrob Chemother 69:2215-2223

13. Buelow E, Bello Gonzalez TDJ, Fuentes S, de Steenhuijsen Piters WAA, Lahti L, Bayjanov JR, Majoor EAM, Braat JC, van Mourik MSM, Oostdijk EAN, Willems RJL, Bonten MJM, van Passel MWJ, Smidt H, van Schaik W (2017) Comparative gut microbiota and resistome profiling of intensive care patients receiving selective digestive tract decontamination and healthy subjects. Microbiome 5:88

14. Halaby T, Al Naiemi N, Kluytmans J, van der Palen J, VandenbrouckeGrauls CM (2013) Emergence of colistin resistance in Enterobacteriaceae 
after the introduction of selective digestive tract decontamination in an intensive care unit. Antimicrob Agents Chemother 57:3224-3229

15. Lubbert C, Faucheux S, Becker-Rux D, Laudi S, Durrbeck A, Busch T, Gastmeier P, Eckmanns T, Rodloff AC, Kaisers UX (2013) Rapid emergence of secondary resistance to gentamicin and colistin following selective digestive decontamination in patients with KPC-2-producing Klebsiella pneumoniae: a single-centre experience. Int J Antimicrob Agents 42:565-570
16. Tascini C, Sbrana F, Flammini S, Tagliaferri E, Arena F, Leonildi A, Ciullo I, Amadori F, Di Paolo A, Ripoli A, Lewis R, Rossolini GM, Menichetti F (2014) Oral gentamicin gut decontamination for prevention of KPC-producing Klebsiella pneumoniae infections: relevance of concomitant systemic antibiotic therapy. Antimicrob Agents Chemother 58:1972-1976 